\title{
The Eucalyptus Cuticular Waxes Contribute in Preformed Defense Against Austropuccinia psidii
}

\author{
Isaneli Batista dos Santos', Mariana da Silva Lopes ${ }^{1}$, Andressa Peres Bini', \\ Bruno Augusto Prohmann Tschoeke', Bruna Aparecida Wruck Verssani', \\ Everthon Fernandes Figueredo', Thais Regiani Cataldi', \\ João Paulo Rodrigues Marques ${ }^{3}$, Luciana Duque Silva ${ }^{4}$, Carlos Alberto Labate ${ }^{1}$ and \\ Maria Carolina Quecine ${ }^{1 *}$
}

\footnotetext{
'Departament of Genetics, "Luiz de Queiroz" College of Agriculture, University of São Paulo, Piracicaba, Brazil, " Departament of Exact Sciences, "Luiz de Queiroz" College of Agriculture, University of São Paulo, Piracicaba, Brazil, ${ }^{3}$ Departament of Phytopathology, "Luiz de Queiroz" College of Agriculture, University of São Paulo, Piracicaba, Brazil, " Departament of Forest Science, "Luiz de Queiroz" College of Agriculture, University of São Paulo, Piracicaba, Brazil
}

\section{OPEN ACCESS}

Edited by:

Jens Staal,

Ghent University, Belgium

Reviewed by:

Walter Gassmann,

University of Missouri, United States

Fei Gao,

University of Missouri, United States

*Correspondence:

Maria Carolina Quecine

mquecine@usp.br

Specialty section: This article was submitted to

Plant Microbe Interactions,

a section of the journal

Frontiers in Plant Science

Received: 26 September 2018

Accepted: 19 December 2018

Published: 09 January 2019

Citation:

Santos IB, Lopes MdS, Bini AP,

Tschoeke BAP, Verssani BAW,

Figueredo EF, Cataldi TR,

Marques JPR, Silva LD, Labate CA and Quecine MC (2019) The

Eucalyptus Cuticular Waxes

Contribute in Preformed Defense

Against Austropuccinia psidii.

Front. Plant Sci. 9:1978.

doi: 10.3389/fp/s.2018.01978
Austropuccinia psidii, the causal agent of myrtle rust, is a biotrophic pathogen whose growth and development depends on the host tissues. The uredospores of $A$. psidii infect Eucalyptus by engaging in close contact with the host surface and interacting with the leaf cuticle that provides important chemical and physical signals to trigger the infection process. In this study, the cuticular waxes of Eucalyptus spp. were analyzed to determine their composition or structure and correlation with susceptibility/resistance to A. psidii. Twenty-one Eucalyptus spp. in the field were classified as resistant or susceptible. The resistance/susceptibility level of six Eucalyptus spp. were validated in controlled conditions using $\mathrm{PPCR}$, revealing that the pathogen can germinate on the eucalyptus surface of some species without multiplying in the host. CG-TOFMS analysis detected 26 compounds in the Eucalyptus spp. cuticle and led to the discovery of the role of hexadecanoic acid in the susceptibility of Eucalyptus grandis and Eucalyptus phaeotricha to A. psidii. We characterized the epicuticular wax morphology of the six previously selected Eucalyptus spp. using scanning electron microscopy and observed different behavior in A. psidii germination during host infection. It was found a correlation of epicuticular morphology on the resistance to $A$. psidii. However, in this study, we provide the first report of considerable interspecific variation in Eucalyptus spp. on the susceptibility to $A$. psidii and its correlation with cuticular waxes chemical compounds that seem to play a synergistic role as a preformed defense mechanism.

Keywords: cuticular waxes, GC-TOF-MS, preformed defense, rust, susceptibility

\section{INTRODUCTION}

Austropuccinia psidii (G. Winter) Beenken (syn. Puccinia psidii) is a basidiomycete that belongs to the Pucciniales order and is the causal agent of myrtle rust (Miranda et al., 2013; Beenken, 2017). The pathogen infects approximately 460 species in 73 genera of the Myrtaceae (Roux et al., 2013; Giblin and Carnegie, 2014; Beenken, 2017). Its hosts include Eucalyptus spp. that 
are important to the forestry industry (Coutinho et al., 1998). Different degrees of severity are observed in Eucalyptus, and the disease occurs primarily in young trees and infects actively growing leaves, shoots, inflorescences and apical buds (Glen et al., 2007). The disease is characterized by the production of yellow and pulverulent pustules containing the uredospores that cause the deformation of the leaves, intense defoliation of the branches, stunted growth and even the death of the plants (Ferreira, 1981). Despite the importance of myrtle rust, the mechanisms of resistance of Eucalyptus spp. to $A$. psidii remain unclear. The host penetration by rust pathogens occurs preferentially through stomata; however, A. psidii penetrates inner Eucalyptus tissues through the cuticle and epidermis following the formation of appressoria (Xavier et al., 2001).

Leaf cuticular waxes cover all the aerial plant surfaces and have a multifunctional role, serving as an interface between the plant and biotic or abiotic stresses; its composition includes a polymeric skeleton of cutin covalently attached to a type of lipid known as waxes (Koch et al., 2010; Yeats and Rose, 2013). Plant cuticles are known to be primary barriers against herbivores and pathogens that perform a key factor in the adaptation and evolution of terrestrial plants and that the cutin monomers released are signaling molecules for both the pathogens and plants (Tucker et al., 2010; Serrano et al., 2014). Leaf surface cuticles have been described to be a source of signals that influence the germination and specificity of the host to biotrophic pathogens (Lazniewska et al., 2012). Thus, the effect of cuticular waxes on pathogen germination has been examined by several authors (Kolattukudy et al., 1995; Inuyang et al., 1999; Reisige et al., 2006; Zabka et al., 2007; Hansjakob et al., 2011; Zabka et al., 2014). These extracts obtained from the leaf surface can induce up to $50 \%$ germination and appressorium production by pathogenic fungi (Reisige et al., 2006). A long-chain hydrocarbon with a $436 \mathrm{MW}$ $\left(\mathrm{C}_{31} \mathrm{H}_{64}\right)$ known as hentriacontane was characterized from an active fraction of Syzygium jambos leaf wax extract. The active fraction induced up to $88 \%$ of uredospore germination and was determined to be involved with the stimulation of rust uredospore germination (Tessmann and Dianese, 2002).

Due to the unique characteristics of the Eucalyptus cuticle, our hypothesis supports the concept that the preformed mechanism plays an important role in Eucalyptus resistance. Thus, we selected Eucalyptus spp. with varying responses to rust myrtle infection in the field and validated the results in controlled conditions. The leaf cuticular wax composition of the six eucalyptus species was characterized using gas chromatography coupled to mass spectrometry (GC-TOF-MS). We also assessed the uredospores germination rate of $A$. psidii exposed to cuticular waxes and specific metabolites identified in susceptible and resistant Eucalyptus spp. The morphology of the Eucalyptus spp. cuticle was observed using electron microscopy. The polyphasic analysis of the leaf cuticle greatly contributed to a better understanding of the dynamics of the early infection process of $A$. psidii on Eucalyptus spp.

\section{MATERIALS AND METHODS}

\section{Susceptibility of Eucalyptus spp. to A. psidii: Field Inference}

Natural Eucalyptus infection by $A$. psidii was evaluated in young trees up to 2 years old. The trees were located at the Anhembi Experimental Station of Forestry Sciences (EECFA), Anhembi, São Paulo, Brazil $\left(22^{\circ} 40^{\prime} \mathrm{S}\right.$ and $\left.48^{\circ} 10^{\prime} \mathrm{W}\right)$. The disease scores representing the percentage of leaves with rust symptoms were based on the Takahashi (2002) scale modified by Zamprogno et al. (2008): S0 (no pustules or healthy plants); S1 (isolated punctate pustules on the limbs and young leaves); S2 (rust pustules generally sparse or occasionally abundant on the limbs and young leaves), and S3 (pustules abundant on the limbs, petioles and leaves, at the tips of branches and the primary stem and apical necrosis). The index disease (ID) was calculated as described by McKinney (1923). The experiment was a randomized design with 21 genotypes (19 species and 2 hybrids) and 72 biological replicates per genotype. Each replicate consisted of one tree.

After the field assessment, species with enough plantlets to further assays: susceptible (Eucalyptus grandis and Eucalyptus phaeotricha) and resistant (Eucalyptus urophylla, Eucalyptus camaldulensis, Eucalyptus urograndis and Eucalyptus robusta) were selected to validate the data in controlled conditions as described by Leite et al. (2013) with modifications (Quecine et al., 2016). Plantlets of each species were grown under greenhouse conditions for 120 days and transferred to a controlled growth chamber under a $12 \mathrm{~h}$ photoperiod $\left(200 \mu \mathrm{mol} \mathrm{m} \mathrm{m}^{-1} \mathrm{~s}^{-1}\right)$ at $20^{\circ} \mathrm{C}$ for acclimatization for 7 days. A suspension of A. psidii MF-1 containing $10^{5}$ uredospores $\mathrm{mL}^{-1}$ and $0.05 \%$ Tween 20 was sprayed onto the plants. The plants were enclosed in transparent plastic bags for the first $48 \mathrm{~h}$ with the first $24 \mathrm{~h}$ in complete darkness at $20^{\circ} \mathrm{C}$ to enable the fungus to germinate. The plants were returned to the growth conditions previously described. The symptoms were assessed in the 3 rd-14th day after inoculation based on the scale adapted from Zamprogno et al. (2008). The experiment was conducted in a completely randomized design.

\section{A. psidii Quantification by qPCR in Contrasting Eucalyptus Species}

The leaves from Eucalyptus grandis, Eucalyptus phaeotricha, Eucalyptus urophylla, Eucalyptus camaldulensis, Eucalyptus urograndis and Eucalyptus robusta were harvested at: 0 hour post inoculation (h.p.i) (control treatment); 72 h.p.i (start of the colonization phase-susceptible species, and no detection of the pathogen-resistant species); 144 h.p.i: colonization of mesophyll cells (susceptible species) and no detection of the pathogen (resistant species); and 336 h.p.i: pustules developed (susceptible species) and no detection of the pathogen (resistant species) based on an assay previously described (Bini et al., 2018). At each time, leaves from the first two pairs of five plantlets per species were collected, immediately frozen in liquid nitrogen and stored at $-80^{\circ} \mathrm{C}$. Leaves of the control plants were collected at 0 h.a.i. The DNA was extracted from $100 \mathrm{mg}$ of leaves using a 
DNeasy Plant Mini Kit (Qiagen) according to the manufacturer's instructions.

The qPCR (Real-Time Quantitative PCR) reaction was performed using an iCycleiQ Real-Time PCR Detection System (BioRad) in a final volume of $25 \mu \mathrm{L}$. The A. psidii genomic DNA quantification in the Eucalyptus spp. leaves was based on an IGS region described by Bini et al. (2018). The A. psidii MF-1 DNA serial dilution was performed in triplicate, and the time-course assay samples were generated in duplicates of all five biological replicates per sampled time.

\section{Eucalyptus spp. Cuticular Wax Extraction}

Cuticular wax from the young leaves of Eucalyptus grandis, Eucalyptus phaeotricha, Eucalyptus urophylla, Eucalyptus camaldulensis, Eucalyptus urograndis and Eucalyptus robusta was extracted as described by Viana et al. (2010) modified by Bini (2016). One milligram of wax was obtained by immersing and gentle agitating the leaves in $5 \mathrm{~mL}$ of chloroform (JT Baker) for $30 \mathrm{~s}$ and vacuum concentration (SpeedVac-Eppendorf) for $20 \mathrm{~min}$. Each replicate consisted of six to eight young leaves from one plantlet. Four plantlets were used for each species.

\section{Chemical Characterization of Eucalyptus spp. Cuticular Waxes Using CG-TOF-MS}

The GC-TOF-MS (Gas Chromatography coupled to Time-OfFlight Mass Spectrometry) analysis was performed immediately after the wax extraction. The samples were derivatized as described by Hoffman et al. (2010) with $30 \mu \mathrm{L}$ of methoxyamine hydrochloride $\left(15 \mathrm{mg} \mathrm{mL}^{-1}\right)$ in pyridine for $16 \mathrm{~h}$ at room temperature in the dark. The samples were trimethylsilylated by adding $30 \mu \mathrm{L}$ of $N$-methyl- $N$-(trimethylsilyl) trifluoroacetamide (MSTFA) containing 1\% trimethylchlorosilane (TMCS) and incubating the mixture at room temperature for $1 \mathrm{~h}$. Thirty microliters of heptane was added after silylation. Stable isotope reference compounds $\left[1 \mathrm{mg} \mathrm{mL}^{-1}\right.$ each of $\left({ }^{13} \mathrm{C}_{3}\right)$-myristic acid, $\left({ }^{13} \mathrm{C}_{4}\right)$ - palmitic acid and $\left({ }^{2} \mathrm{H}_{4}\right)$ - succinic acid] were added to the samples prior to derivatization and used as external standards for quality control. The derivatized samples were analyzed as described by Gullberg et al. (2004). Blank control samples and a series of $n$-alkanes (C12-C40) were also used to obtain the retention indices (Schauer et al., 2005).

One microliter of each derivatized sample was injected splitless into a gas chromatograph 7890A (Agilent Technologies, Santa Clara, United States) coupled with a Comb-xt Autosampler (Leap Technologies, Carrboro, United States). The injector temperature was $280^{\circ} \mathrm{C}$; the septum purge flow rate was $20 \mathrm{~mL} \mathrm{~min}{ }^{-1}$, and the purge was turned on after $60 \mathrm{~s}$. The gas flow rate through the column was $1 \mathrm{~mL} \mathrm{~min}^{-1}$. The column used for the GC $\times$ GC separation was a DB-5 $(20 \mathrm{~m} \times 0.18 \mathrm{~mm} \times 0.18 \mu \mathrm{m}$; Agilent Technologies, Santa Clara, United States) as the first-dimension column and a RTX-17 $(0.9 \mathrm{~m} \times 0.10 \mathrm{~mm} \times 0.10 \mu \mathrm{m}$; Restek Corporation, U.S., Bellefonte) for the second-dimension column. The column temperature was held at $80^{\circ} \mathrm{C}$ for $2 \mathrm{~min}$, increased by $10^{\circ} \mathrm{C} \mathrm{min}^{-1}$ to $305^{\circ} \mathrm{C}$ and held for $10 \mathrm{~min}$. The column effluent was introduced into the ion source of a GC $\times$ GC/TOFMS (Pegasus 4D, Leco Corp., St. Joseph, United States). The transfer line and the ion source temperatures were 280 and $250^{\circ} \mathrm{C}$, respectively. The ions were generated using a $70 \mathrm{eV}$ electron beam at an ionization current of $2.0 \mathrm{~mA}$, and $10 \mathrm{spectra} / \mathrm{s}$ were recorded in the mass range $\mathrm{m} / \mathrm{z} 45-800$.

ChromaTOF software v. 4.51 (Leco Corp., St. Joseph, United States) was used to correct the baseline and export all the MS files into a NetCDF format. Peak detection, retention time alignment and library matching were performed using the Target Search package (Cuadros-Inostroza et al., 2009). Metabolites were identified by comparing their retention indexes $( \pm 2 \mathrm{~s})$ and spectra (similarity $>600$ ) against the compounds stored in the Golm-Metabolome-Database ${ }^{1}$ (Kopka et al., 2005). Metabolite intensities were normalized using dry weight and total ion chromatogram (TIC).

\section{Influence of Cuticular Wax on A. psidii Germination}

The cuticular waxes from Eucalyptus grandis, Eucalyptus phaeotricha, Eucalyptus urophylla, Eucalyptus camaldulensis, Eucalyptus urograndis and Eucalyptus robusta were obtained as described above. One milligram of extracted waxes was diluted in $1 \mathrm{~mL}$ of dichloromethane (JT Baker) to remove chloroform residues and vacuum concentrated (SpeedVac-Eppendorf). The waxes were solubilized in $1 \mathrm{~mL}$ of dichloromethane (JT Baker) and sonicated for $10 \mathrm{~min}$. This final solution was used in the germination assay. The uredospore solution of A. psidii MF-1 was prepared separately in mineral oil (Sigma Aldrich) $\left(10^{5}\right.$ uredospores per Petri dish), which was mixed with $20 \mathrm{ppm}$ of the cuticle extracts (Tessmann and Dianese, 2002). The uredospore solution was inoculated in Petri dishes containing solid water agar medium $\left(8 \mathrm{~g} \mathrm{~L}^{-1}\right)$ amended with mineral oil and cuticle extracts and incubated for $24 \mathrm{~h}$ at $20^{\circ} \mathrm{C}$ in the dark. Five hundred uredospores were observed for each treatment per replicate, and the germination rate was calculated based on the number of uredospores with a germ tube. The experiment was conducted in three randomized blocks. Water, mineral oil and dichloromethane were considered to be the controls. Uredospore germination was observed using a light microscope (Aziophot) with a digital coupled camera (Zeiss).

\section{Hexadecanoic Acid Effects on A. psidii Germination}

To validate the results obtained using GC-TOF-MS, a bioassay was performed using commercial palmitic acid (hexadecanoic acid) (Sigma Aldrich) and a uredospore solution of A. psidii MF-1 ( $10^{5}$ per Petri dish) diluted in mineral oil (Sigma Aldrich). The palmitic acid was diluted in dichloromethane (JT Baker) at concentrations of 0 (control), 0.5, 2.5, 5.0, 10 and $20 \mathrm{ppm}$ and combined with the solution of uredospores before inoculation in Petri dishes with solid water agar medium $\left(8 \mathrm{~g} \mathrm{~L}^{-1}\right)$ and incubation for $24 \mathrm{~h}$ at $20^{\circ} \mathrm{C}$ in the dark. Germination rates were

\footnotetext{
${ }^{1}$ http://gmd.mpimp-golm.mpg.de/
} 
TABLE 1 | Susceptibility level of Eucalyptus spp. to A. psidii.

\begin{tabular}{|c|c|c|c|c|c|c|}
\hline \multirow[t]{2}{*}{ Species } & \multicolumn{4}{|c|}{ Susceptibility scale $(\%)^{a}$} & \multirow[t]{2}{*}{ Classification $^{\mathbf{b}}$} & \multirow[t]{2}{*}{ ID (\%) } \\
\hline & so & S1 & S2 & S3 & & \\
\hline Eucalyptus botryoides & 44.44 & 20.83 & 26.39 & 8.33 & Susceptible & 45.65 \\
\hline Eucalyptus brassiana & 91.67 & 1.39 & 2.78 & 4.17 & Low resistance & 9.00 \\
\hline Eucalyptus camaldulensis & 70.83 & 19.44 & 8.33 & 1.39 & Low resistance & 18.65 \\
\hline Eucalyptus cloeziana & 75.00 & 11.11 & 12.50 & 1.39 & Low resistance & 18.65 \\
\hline Eucalyptus deglupta & 34.72 & 19.44 & 34.72 & 11.11 & Susceptible & 56.58 \\
\hline Eucalyptus dunni & 72.22 & 20.83 & 5.56 & 1.39 & Low resistance & 16.72 \\
\hline Eucalyptus exserta & 98.61 & 1.39 & 0.00 & 0.00 & Low resistance & 0.64 \\
\hline Eucalyptus grandis & 47.22 & 25.00 & 20.83 & 6.94 & Susceptible & 40.51 \\
\hline Eucalyptus microcorys & 83.33 & 12.50 & 2.78 & 1.39 & Low resistance & 10.29 \\
\hline Eucalyptus paniculata & 91.67 & 5.56 & 1.39 & 1.39 & Low resistance & 5.79 \\
\hline Eucalyptus pellita & 93.06 & 2.78 & 2.78 & 1.39 & Low resistance & 5.79 \\
\hline Eucalyptus phaeotricha & 45.83 & 26.39 & 4.17 & 23.61 & Susceptible & 48.87 \\
\hline Eucalyptus pilularis & 75.00 & 19.44 & 1.39 & 4.17 & Low resistance & 16.08 \\
\hline Eucalyptus propínqua & 94.44 & 2.78 & 1.39 & 1.39 & Low resistance & 4.50 \\
\hline Eucalyptus resinifera & 100.00 & 0.00 & 0.00 & 0.00 & High resistance & 0.00 \\
\hline Eucalyptus robusta & 97.22 & 0.00 & 0.00 & 2.78 & Low resistance & 3.86 \\
\hline Eucalyptus saligna & 65.28 & 31.94 & 2.78 & 0.00 & Low resistance & 17.36 \\
\hline Eucalyptus tereticornis & 87.50 & 6.94 & 4.17 & 1.39 & Low resistance & 9.00 \\
\hline Eucalyptus toreliodora & 100.00 & 0.00 & 0.00 & 0.00 & High resistance & 0.00 \\
\hline Eucalyptus urograndis & 83.33 & 11.11 & 5.56 & 0.00 & Low resistance & 10.29 \\
\hline Eucalyptus urophylla & 93.06 & 4.17 & 1.39 & 1.39 & Low resistance & 5.14 \\
\hline
\end{tabular}

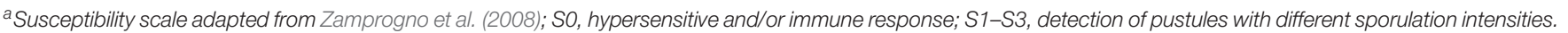

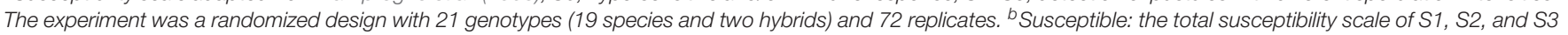

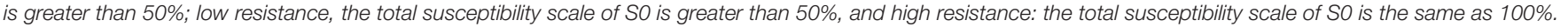

${ }^{C} I D$, disease index was calculated as described by McKinney (1923).

obtained as described above. The experiment was conducted in a randomized block design with six hexadecanoic acid concentrations using three replicates (Petri dishes) per treatment.

\section{Scanning Electron Microscopy}

We examined the morphology of the epicuticle wax morphology by evaluating the middle third adaxial leaf surface of non-inoculated and inoculated (144 h.p.i.) plantlets of Eucalyptus grandis, Eucalyptus phaeotricha, Eucalyptus urophylla, Eucalyptus camaldulensis, Eucalyptus urograndis and Eucalyptus robusta. The leaves were sampled and fixed in Karnovsky solutions (Karnovsky, 1965), washed in $0.1 \mathrm{M}$ phosphate buffer and post fixed in $1 \%$ osmium tetroxide in $0.1 \mathrm{M}$ phosphate buffer ( $\mathrm{pH}$ 7.2). The samples were washed three times in distilled water and then dehydrated in graded acetones $(10 \%$ $1 \times, 30 \% 1 \times, 50 \% 1 \times, 70 \% 1 \times, 90 \% 1 \times, 100 \% 2 \times$, for $15 \mathrm{~min}$ each). All these steps were performed at room temperature. The samples were dried to their critical point (Horridge and Tamm, 1969), glued on aluminum stubs and sputter coated with gold. The samples were examined at $20 \mathrm{kV}$ using an LEO VP435 (Zeiss, Oberkochen, Germany) scanning electron microscope.

\section{Statistical Analysis}

The profile of the metabolites from the cuticular waxes was submitted to multivariate analysis to visualize the separation among the Eucalyptus spp. using the program Metaboanalyst ${ }^{2}$. Principal component analysis (PCA) was also utilized to identify the tendency of group separation, and an ANOVA (Analysis of variance) was used to identify differentially abundant metabolites among the groups $(p<0.05)$, followed by a comparison test of Scott-Knott averages $(p<0.05)$ (Chong et al., 2018). The results of fungal quantification by qPCR. The germination rate of $A$. psidii in different cuticular waxes and hexadecanoic acid concentrations were submitted to an ANOVA, followed by Scott-Knott's our Tukey tests $(p<0.05)$ using software $\mathrm{R}$ (version 3.4.1).

\section{RESULTS}

\section{Evaluation of the Eucalyptus spp. Rust Susceptibility}

Among the 19 species and two hybrids evaluated in the field, just two species were classified as S0-high level of resistance to the pathogen (Eucalyptus resinifera and Eucalyptus toreliodora); four species were classified as susceptible to $A$. psidii, i.e., more than $50 \%$ of the individuals were categorized in the S1, S2 and S3 scale (Eucalyptus botryoides, Eucalyptus deglupta, Eucalyptus grandis and Eucalyptus phaeotricha) with IDs ranging from 40.51 to

\footnotetext{
${ }^{2}$ http://www.metaboanalyst.ca/
} 

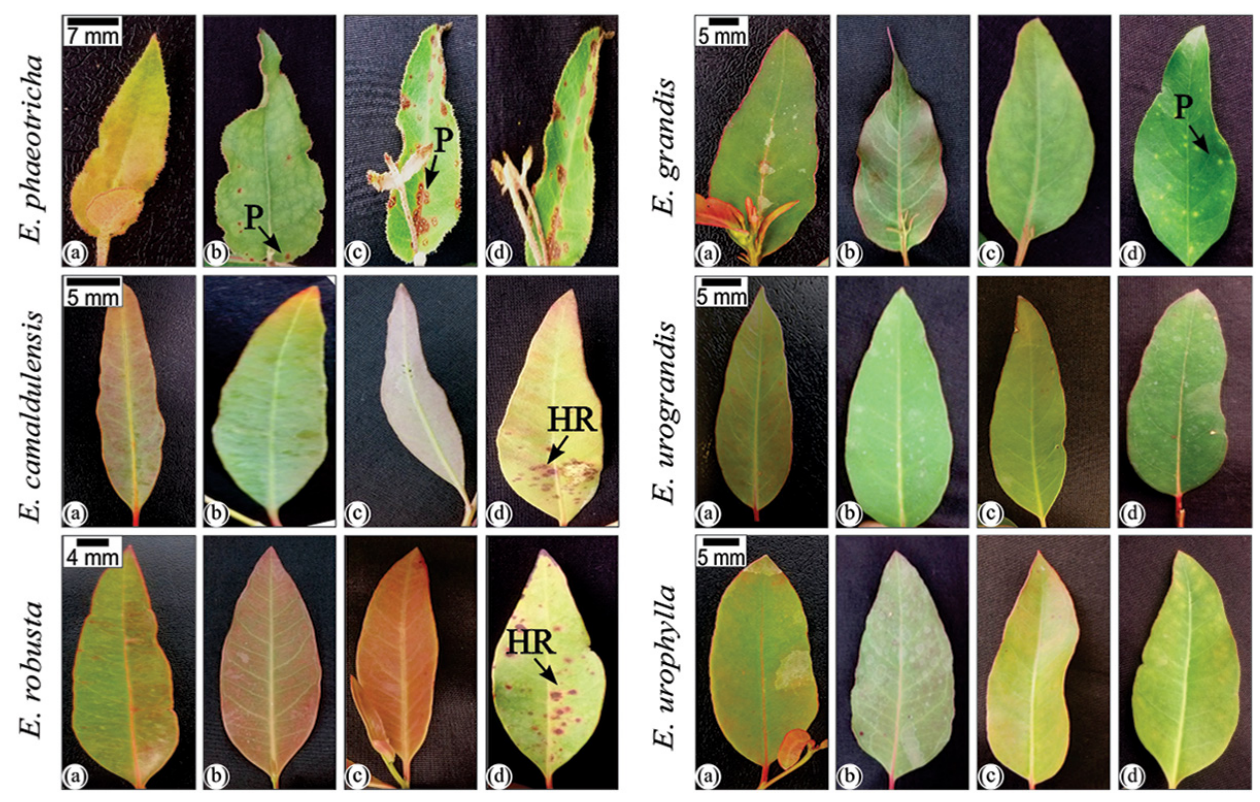

FIGURE 1 | Infection process of $A$. psidii (MF1) in Eucalyptus spp. in controlled conditions. Legend: (a): 0 h.p.i. (hours post inoculation); (b): 72 h.p.i.; (c): 144 h.p.i.; (d): 336 h.p.i. Pustules in symptomatic leaves from Eucalyptus phaeotrica and Eucalyptus grandis are indicated by black arrows. The hypersensitive response in Eucalyptus camaldulensis and Eucalyptus robusta leaves is indicated by white arrows.

TABLE 2 | Quantification of A. psidii (MF1) during Eucalyptus spp. infection.

\begin{tabular}{|c|c|c|c|c|}
\hline \multirow[t]{2}{*}{ Species } & \multicolumn{4}{|c|}{ A. psidii quantification (DNA pg)* } \\
\hline & 0 h.a.i & 72 h.a.i & 144 h.a.i & 336 h.a.i \\
\hline Eucalyptus grandis & $0.21( \pm 0.09)^{b}$ & $0.28( \pm 0.16)^{b}$ & $0.58( \pm 0.42)^{\mathrm{b}}$ & $2.71( \pm 1.31)^{\mathrm{a}}$ \\
\hline Eucalyptus phaeotricha & $0.42( \pm 0.09)^{\mathrm{C}}$ & $0.95( \pm 0.41)^{\mathrm{C}}$ & $6.75( \pm 3.43)^{b}$ & $11.8( \pm 6.53)^{\mathrm{a}}$ \\
\hline Eucalyptus urograndis & $0.51( \pm 0.12)^{\mathrm{a}}$ & $0.14( \pm 0.08)^{b}$ & $0.00( \pm 0.00)^{c}$ & $0.00( \pm 0.00)^{\mathrm{c}}$ \\
\hline Eucalyptus urophylla & $0.05( \pm 0.04)^{b}$ & $0.29( \pm 0.13)^{\mathrm{a}}$ & $0.00( \pm 0.00)^{\mathrm{c}}$ & $0.00( \pm 0.00)^{\mathrm{c}}$ \\
\hline Eucalyptus robusta & $0.20( \pm 0.13)^{\mathrm{a}}$ & $0.04( \pm 0.04)^{\mathrm{a}}$ & $0.00( \pm 0.00)^{b}$ & $0.00( \pm 0.00)^{b}$ \\
\hline Eucalyptus camaldulensis & $0.04( \pm 0.04)^{b}$ & $0.21( \pm 0.12)^{\mathrm{a}}$ & $0.00( \pm 0.00)^{\mathrm{c}}$ & $0.00( \pm 0.00)^{\mathrm{c}}$ \\
\hline
\end{tabular}

$56.30 \%$. Other species demonstrated a low level of resistance, and more than $50 \%$ of the individuals were asymptomatic to rust (ID: 0.64-18.65\%) (Table 1).

The susceptible/resistance level of the Eucalyptus spp. against A. psidii was validated in controlled condition: Eucalyptus urophylla, Eucalyptus camaldulensis, Eucalyptus robusta and Eucalyptus urograndis were classified as S0, i.e., resistant to $A$. psidii in these conditions with a hypersensitive response in Eucalyptus camaldulensis and Eucalyptus robusta at 336 h.p.i. The susceptibility of Eucalyptus grandis and Eucalyptus phaeotricha was confirmed by visualization of the typical symptoms of rust: chlorotic stains which turned into pustules, resulting in a mass of uredospores. The symptoms on the Eucalyptus phaeotricha leaves occurred earlier compared to those on Eucalyptus grandis (Figure 1).

The infection was also monitored over time by the temporal quantification of $A$. psidii in the leaf tissues of
Eucalyptus grandis, Eucalyptus phaeotricha, Eucalyptus urophylla, Eucalyptus camaldulensis, Eucalyptus urograndis and Eucalyptus robusta using qPCR. A. psidii was not detected in non-inoculated control samples. The pathogen was detected up to 72 h.p.i in all the species inoculated with $A$. psidii uredospores ranging between 0.04 (Eucalyptus camaldulensis) to $0.95 \mathrm{pg}$ (Eucalyptus phaeotricha). Non-pathogenicity was detected at 144 and 336 h.p.i. in the resistant species (Eucalyptus urophylla, Eucalyptus camaldulensis, Eucalyptus urograndis and Eucalyptus robusta) (Table 2).

\section{Eucalyptus spp. Cuticle Wax Characterization}

GC-TOF-MS analysis enabled the identification of 26 metabolites present in the cuticular waxes from the Eucalyptus spp. Two metabolites of the 26 compounds were only identified 

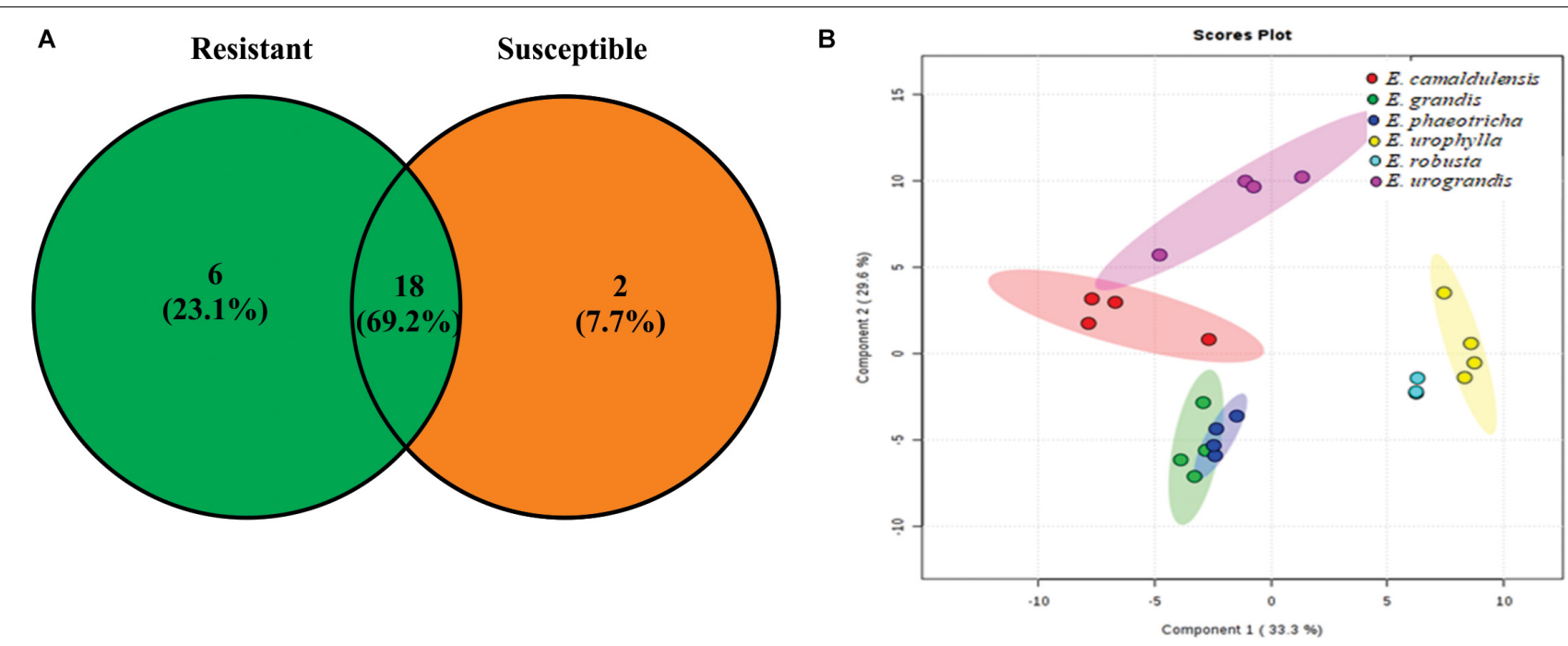

FIGURE 2 | Metabolic profile from the cuticle waxes of susceptible (Eucalyptus grandis and Eucalyptus phaeotricha) and resistant (Eucalyptus camaldulensis, Eucalyptus urophylla, Eucalyptus robusta and Eucalyptus urograndis) Eucalyptus species against $A$. psidii. (A) The Venn diagram shows the number of overlapping metabolites among the resistant (R) and susceptible (S) treatments. (B) Principal component analysis (PCA) of the metabolic profile of cuticle Eucalyptus spp. in which susceptible species (Eucalyptus grandis and Eucalyptus phaeotricha) are represented by green and blue, respectively, and the resistant plants (Eucalyptus camaldulensis, Eucalyptus urophylla, Eucalyptus robusta and Eucalyptus urograndis) are shown in red, yellow, light blue and pink colors, respectively.

in the susceptible species of Eucalyptus, and six were exclusive to resistant Eucalyptus species (Figure 2A). The total metabolites obtained from the cuticular waxes were submitted to multivariate analysis to visualize the separation among the treatments in relation to the metabolic content. The PCA revealed a clear tendency of the clustering among susceptible (Eucalyptus grandis and Eucalyptus phaeotricha) and resistant (Eucalyptus camaldulensis, Eucalyptus urograndis, Eucalyptus robusta and Eucalyptus urophylla) species. The sum of the first two principal components explained $54.8 \%$ of the total variance (Figure 2B).

The cuticular wax compounds were classified as fatty acyls (38\%), alkanes (23\%), steroids (12\%), organooxygen compounds (11\%), hydrocarbons (4\%), keto acids (4\%), carboxylic acids (4\%) and cinnamic acids (4\%). Twenty-three compounds identified in this study have been previously described to be components of plant cuticular waxes (Table 3). The heat map obtained shows that among the identified metabolites previously described as cuticular wax compounds, hexadecanoic acid is present only in Eucalyptus grandis and Eucalyptus phaeotricha and absent in the resistant species (Figure 3).

\section{Germination Rate of $A$. psidii in Cuticle Extracts and Hexadecanoic Acid}

The germination rate of $A$. psidii was significantly higher in the media supplemented with 20 ppm cuticle extract of Eucalyptus grandis (44.06\%) followed by Eucalyptus urograndis (16.26\%). With the exception of Eucalyptus grandis, the addition of cuticular wax from Eucalyptus spp. did not seem to influence the germination rates of the uredospores compared to mineral oil. Non-significant germination was observed using only the solvent dichloromethane and water (Figure 4A). To confirm the ability of hexadecanoic acid to induce germination, the germination rate of $A$. psidii was determined at 24 h.p.i. We observed the highest germination rate of $8 \%$ using $5.0 \mathrm{ppm}$ hexadecanoic acid. The data showed a polynomial curve from 0 to $20 \mathrm{ppm}$. The lowest rate of $1.46 \%$ was observed in the absence of hexadecanoic acid (Figure 4B).

\section{Epicuticular Wax Morphology and A. psidii Germination in vivo}

It was possible to group the six Eucalyptus spp. into three different groups based on the epicuticular wax morphology: Group I is comprised of species that contain parallel platelets wax crystals and include Eucalyptus grandis, Eucalyptus urograndis, and Eucalyptus robusta and Eucalyptus urophylla (Figures 5ad). Group II includes Eucalyptus phaeotricha in which the wax crystals are absent, and the cuticle presents a smooth surface comprised of a thin wax film that can be folded in some regions (Figure 5e). Group III includes Eucalyptus camaldulensis and exhibits epicuticular wax distributed as tubes or threads (Figure 5f). Another difference among them is that only Eucalyptus phaeotricha possess a pubescent leaf covered by nonglandular trichomes (data not shown).

There are some differences in the members of Group 1 in the orientation and size of the platelets. Eucalyptus grandis and Eucalyptus urograndis possess epicuticular wax crystals of different sizes (Figures 5a1-2, b1-2). The large wax crystals are primarily located on the epidermis anticlinal walls, while the smaller ones are on the periclinal walls. In Eucalyptus robusta, the majority of the wax plates were parallel and arranged perpendicularly to the proximodistal leaf axis (Figures 5d1-2). Eucalyptus urophylla possesses parallel wax plates, but they seem to be distributed in a different direction (Figures 5c1-2). 
TABLE 3 | The classification of 26 metabolites presents in cuticular wax Eucalyptus species according of The Human Metabolome Database.

\begin{tabular}{|c|c|c|c|}
\hline Metabolite & Class $^{a}$ & Organism & Reference \\
\hline Alpha-D-Galactopyranosyl-(1,4) & Organooxygen compounds & Plant & Horbowicz et al., 1998 \\
\hline Androst-4-en-3,17-dione & Steroids and Steroid derivatives & Fungal & Faramarzi et al., 2008 \\
\hline Cinnamic acid, 4-hydroxy & Cinnamic acids and derivatives & Plant & Freitas et al., 2016 \\
\hline Corticosterone & Steroids and Steroid derivatives & Animal & Samtani and Jusko, 2007 \\
\hline Docosan-1-ol & Fatty Acyls & Plant & Stashenki and Martínez, 2012 \\
\hline Docosane & Alkanes & Plant & Lytovchenko et al., 2009 \\
\hline Eicosane & Alkanes & Plant & Asha et al., 2017 \\
\hline Erythronic acid & Organooxygen compounds & Human & Nikolova et al., 2016 \\
\hline Heneicosane & Alkanes & Plant & Bini, 2016; Moussa and Almaghrabi, 2016 \\
\hline Heptadecanoic acid & Fatty Acyls & Plant & Moussa and Almaghrabi, 2016 \\
\hline Hexacosane & Alkanes & Plant & Kumar et al., 2017 \\
\hline Hexadecanoic acid & Fatty Acyls & Plant & Moussa and Almaghrabi, 2016 \\
\hline Hexadecenoic acid & Fatty Acyls & Plant & Cahoon et al., 1994; Moussa and Almaghrabi, 2016 \\
\hline Nonacosane & Alkanes & Plant & Lytovchenko et al., 2009 \\
\hline Octacosanoic acid & Fatty Acyls & Plant & Lytovchenko et al., 2009 \\
\hline Octadecadienoic acid & Fatty Acyls & Plant & Bini, 2016; Moussa and Almaghrabi, 2016 \\
\hline Octadecan-1-ol & Fatty Acyls & Plant & Lytovchenko et al., 2009 \\
\hline Octadecanoic acid & Fatty Acyls & Plant & Moussa and Almaghrabi, 2016; Lytovchenko et al., 2009 \\
\hline Octadecenoic acid, 6-(Z) & Fatty Acyls & Plant & Rajeswari and Rani, 2015; Vijisaral and Arumugam, 2014 \\
\hline Octadecenoic acid, 9-(Z) & Fatty Acyls & Plant & Moussa and Almaghrabi, 2016 \\
\hline Pentacosane & Organooxygen compounds & Plant & Kumar et al., 2017 \\
\hline Pentadecane & Saturated hydrocarbons & Plant & Lytovchenko et al., 2009 \\
\hline Pregnane-3alpha & Steroids and Steroid derivatives & Plant & Cioffi et al., 2006 \\
\hline Prephenic acid & Keto acids and derivatives & Plant & Bini, 2016 \\
\hline Threonine & Carboxylic acids and derivatives & Plant & Bini, 2016 \\
\hline Tricosane & Alkanes & Plant & Casuga et al., 2016 \\
\hline
\end{tabular}

a The class of metabolites was determinate in The Human Metabolome Database. Access in May 2, 2018. Available in: http://www.hmdb.ca/.

We found germinated uredospores in all species at 24 h.p.i (data not shown). In the susceptible species Eucalyptus grandis and Eucalyptus phaeotricha, germ tubes were observed at 144 h.p.i. along with the possible presence of a degraded cuticle represented by grooves (Figure 5a3). Pustules and a substantial amount of trichomes were only observed in Eucalyptus phaeotricha (Figure 5e3). In Eucalyptus urograndis, described as a low resistance species, we also observed germinated uredospores (Figure 5b3). However, the germination was visually higher than the germinated uredospores found in Eucalyptus urophylla and Eucalyptus camaldulensis (Figures 5c3-F3). Non-germinated uredospores were found in Eucalyptus robusta (Figure 5d3).

\section{DISCUSSION}

The susceptibility level to A. psidii and the ID of Eucalyptus spp. revealed high variability among the species, as well as individuals within the same species. The susceptibility and resistance levels found in Eucalyptus grandis, Eucalyptus cloeziana, Eucalyptus microcorys, Eucalyptus robusta, Eucalyptus tereticornis, Eucalyptus urograndis, Eucalyptus saligna and Eucalyptus urophylla have been reported previously (Carvalho et al., 1998; Zauza et al., 2010; Carnegie and Lidbetter, 2012; Silva et al., 2014). However, we observed low resistance in
Eucalyptus cloeziana, Eucalyptus dunii and Eucalyptus microcorys that had been previously described as species susceptible to A. psidii (Dianese et al., 1984; Kawanishi et al., 2009; Zauza et al., 2010; Carnegie and Lidbetter, 2012; Silva et al., 2014). Our research is the first report that describes the susceptibility of Eucalyptus botryoides and Eucalyptus deglupta to rust, as well as the resistance of Eucalyptus brassiana, Eucalyptus exserta and Eucalyptus toreliodora to the disease.

The variability within the Eucalyptus species has resulted in a controversial susceptibility classification of A. psidii, which could be explained by the high level of allogamy found in Eucalyptus. The pathogen A. psidii has also been described to possess a wide genetic variability (Quecine et al., 2014). In addition, it is known that the incidence and severity of the disease varies among genotypes within the same species, geographic region and time of the year (Alfenas et al., 2004), demonstrating the importance of the genotype-environment interaction on myrtle rust studies.

In controlled conditions, we validated the data obtained in the field. The assay demonstrated the ability of the uredospores from Eucalyptus grandis to infect the susceptible species Eucalyptus phaeotrica. In addition, the symptoms of the disease were visualized early in Eucalyptus phaeotrica when compared to Eucalyptus grandis. At 336 h.p.i., Eucalyptus camaldulensis and Eucalyptus robusta showed a hypersensitive response, which was not observed in Eucalyptus urophylla and Eucalyptus urograndis. The different defense responses exhibited in the species evaluated 


Metabolite
Threonine
Pentadecane
Cinnamic acid
Eicosane
Hexadecenoic acid
Hexadecanoic acid
Prephenic acid
Heneicosane
Heptadecanoic acid
Octadecan-1-ol
Docosane
Octadecadienoic acid
Octadecenoic acid 6 (Z)
Octadecenoic acid 9 (Z)
Octadecanoic acid
Tricosane
Pentacosane
Docosanol
Hexacosane
a-D-Galactopyranosyl
Nonacosane
Pregnane-3a
Ocatacosanoic acid

\section{Classification}

Organic Acids

Organic Acids

N/A

Alkanes

Lipids

Fatty Acids

Organic Acids

Alkanes

Lipids

Lipids

Fatty Acids

Lipids

Fatty Acids

Fatty Acids

Fatty Acids

Alkanes

Lipids

Fatty Acids

Alkanes

Lipids

Alkanes

Lipids

Lipids

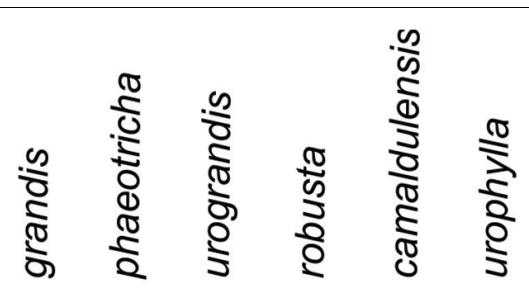

ய

山і
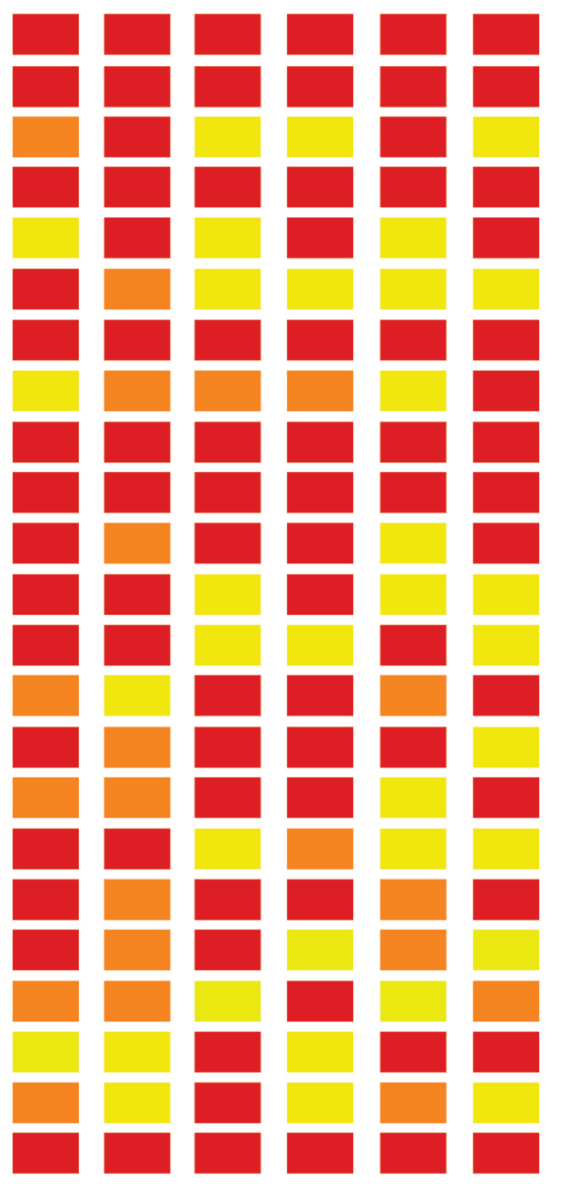

FIGURE 3 | Abundance of metabolites present in the cuticle wax from susceptible (Eucalyptus grandis and Eucalyptus phaeotricha) and resistant (Eucalyptus urograndis, Eucalyptus robusta, Eucalyptus camaldulensis and Eucalyptus urophylla) Eucalyptus species. The data were submitted to an ANOVA followed by the Scott-Knott averages comparison test $(p<0.05)$ using the program Sisvar (v. 5. 6). Red color: indicates greater abundance of the metabolites between Eucalyptus spp.; orange color: less abundance of the metabolites between species, and the yellow color: indicates the absence of the metabolites in plants.

against $A$. psidii reflect the enormous complexity in the plant responses. The SYBR Green-based qPCR assay was used for the first time to detect $A$. psidii on six different Eucalyptus species in initial infection times, validating the sensitivity of the set IGS7/IGS9 primers used to quantify the rust pathogen in Eucalyptus grandis (Bini et al., 2018).

The qPCR corroborated the field results. Temporal monitoring of $A$. psidii showed its presence in a very low abundance until 72 h.p.i in all the species, independently of their susceptibly level. After 72 h.p.i., A. psidii was found only in Eucalyptus grandis and Eucalyptus phaeotricha (susceptible species). Our data is consistent with that of Xavier et al. (2001) and Leite (2012). The authors compared the A. psidii infection process in two contrasting genotypes of Eucalyptus grandis and verified that fungal germination, appressoria formation and penetration occur within 12 h.p.i., independent of the genotype. The defense response starts in the resistant species at 24 h.p.i. After 72 h.p.i, is not possible to detect the pathogen in the resistant hosts, while in the susceptible plants, a succession of events occurs, including mesophyll colonization, development and sporulation pustules. The success of the A.psidii x Eucalyptus interaction is primarily defined in the first stage of infection, and 


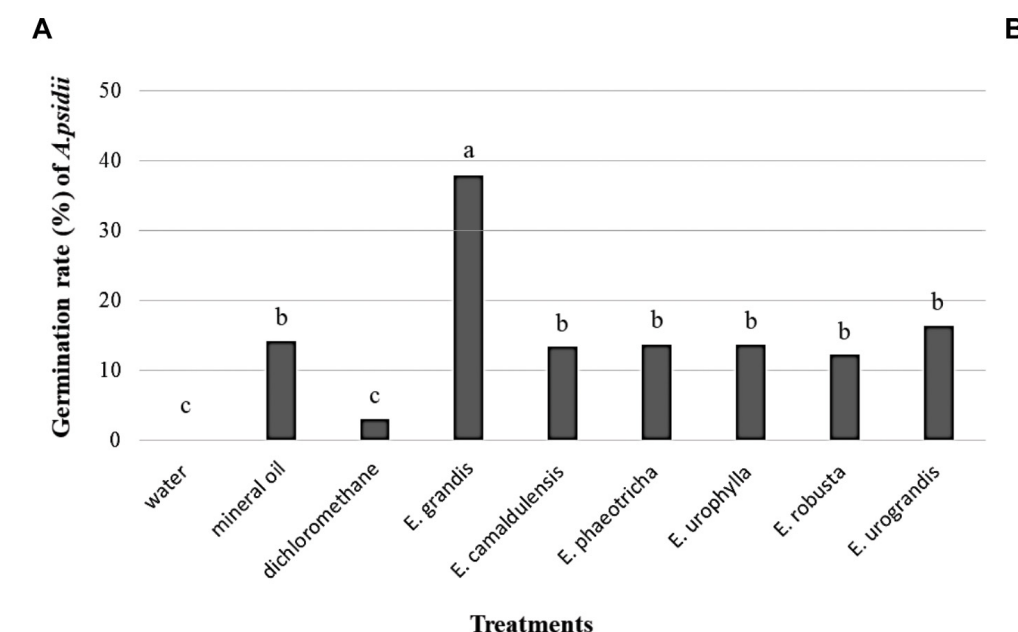

B

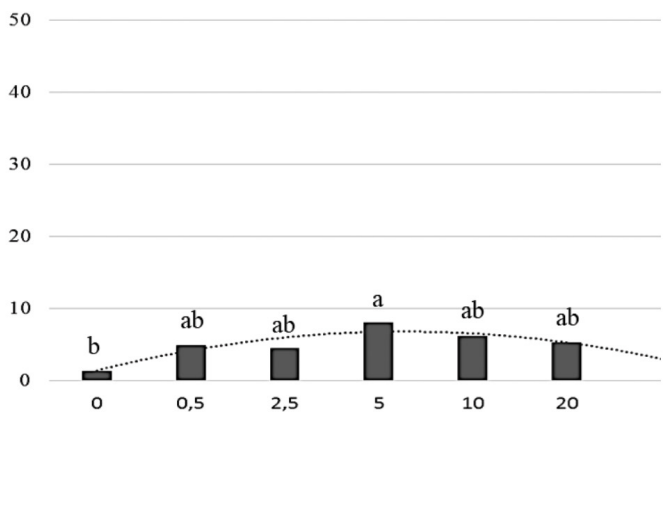

Hexadecanoic acid concentration (ppm)

FIGURE 4 | The germination rate of the A. psidii uredospores (MF1) at 24 h.p.i (A) Agar-water medium with or without cuticular extract from Eucalyptus species. (B) Agar-water medium with palmitic acid (hexadecanoic acid). The data with equal letters did not differ statistically ( $D<0.05)$ using the Scott-Knott (A) and Tukey (B) averages comparison test.

the preformed mechanisms probably play an important role in resistance. Further, the qPCR assay to quantify $A$. psidii should be proceed with other Eucalyptus species.

GC-TOF-MS identified 26 compounds from the cuticular waxes of Eucalyptus leaves. Twenty-three compounds were plant specific, belonging to different classes, such as fatty acyls, alkanes, steroids and hydrocarbon carboxylic acids. Commonly, the compounds of cuticular waxes are derived from very long chain fatty acids (VLCFA), including alkanes, alcohols, and sterols as found in this study (Racovita et al., 2015). The fatty acids in the cuticles of plants and insects have significant effects on spore germination and fungal differentiation, and may be toxic, fungistatic and stimulatory for some pathogenic species. For example, Golebiowski et al. (2008) obtained the profiles of cuticular fatty acids of three species (Calliphora vicina, Dendrolimus pini and Galleria mellonella) in relation to the susceptibility to infection caused by Conidiobolus coronatus. The species resistant to $C$. vicina had a different lipid profile compared to the susceptible species D. pini and G. mellonella. The exclusive presence of three fatty acids in the cuticle of the resistant genotype could inhibit fungal growth and reduce the production of conidia. Our data revealed differences in the lipid profile among Eucalyptus spp. resistant and susceptible to A. psidii in a manner consistent with these results.

We found a specific fatty acid, hexadecanoid acid, in susceptible Eucalyptus grandis and Eucalyptus phaeotricha that improved the uredospore germination rates of $A$. psidii. The role of this compound in the biosynthesis of cuticular wax is highly diverse. Hexadecanoic acid participates in the biosynthetic pathways of fatty acids, cutin, suberin, wax, unsaturated fatty acids and secondary metabolites from plants and contributes to the elongation and degradation of fatty acids (Kanehisa and Goto, 2000).

Unexpectedly, only the cuticle waxes from Eucalyptus grandis stimulated the germination of $A$. psidii uredospores, and the germination rate in Eucalyptus phaeotricha did not differ from the control. Our data is supported by other research, such as that of Song-Jiang et al. (2014) who used cuticular waxes from pingguoli pear to stimulate the germination and mycelial growth of Alternaria alternata. Another study showed that an epicuticular wax extract of wheat leaf (Triticum compactum L.) had an active component capable of inducing up to $50 \%$ the formation of the germ tube, appressorium, substomatal vesicle and penetrating hyphae of Puccinia graminis f.sp. tritici (Reisige et al., 2006). These data enhance the importance of cuticular wax as physical and chemical signaling patterns in the recognition of the host by the pathogen.

Tessmann and Dianese (2002) observed that a long-chain hydrocarbon with $436 \mathrm{MW}$ (C31H64), hentriacontane, obtained from S. jambos leaf wax extract could induce uredospore germination up to $88 \%$ in $A$. psidii. We observed that the effect of hexadecanoic acid on the $A$. psidii germination rate was lower than in the media supplemented with Eucalyptus cuticular waxes. However, our data confirm the influence of hexadecanoic acid on the susceptibility of Eucalyptus spp. to the pathogen A. psidii and suggest a complex A. psidii x Eucalyptus spp. interaction related to probable physical and chemical signaling.

Our data also revealed global differences in the lipid profile between Eucalyptus spp. resistant and susceptible to A. psidii, and not only the chemical profile of possible preformed mechanism related to resistance in Eucalyptus spp. was evaluated. It was possible to assemble Eucalyptus spp. in three groups based on their epicuticular wax morphologies. In the s, Hallam and Chambers (1970) undertook a large study to characterize the wax morphology from a survey of 315 Eucalyptus species and classified them in groups. These authors found that Eucalyptus camaldulensis has the most plastic epicuticular wax. In this study, we observed that Eucalyptus camaldulensis has tubes or threads-shaped epicuticular wax that resemble the Eucalyptus globulus wax 

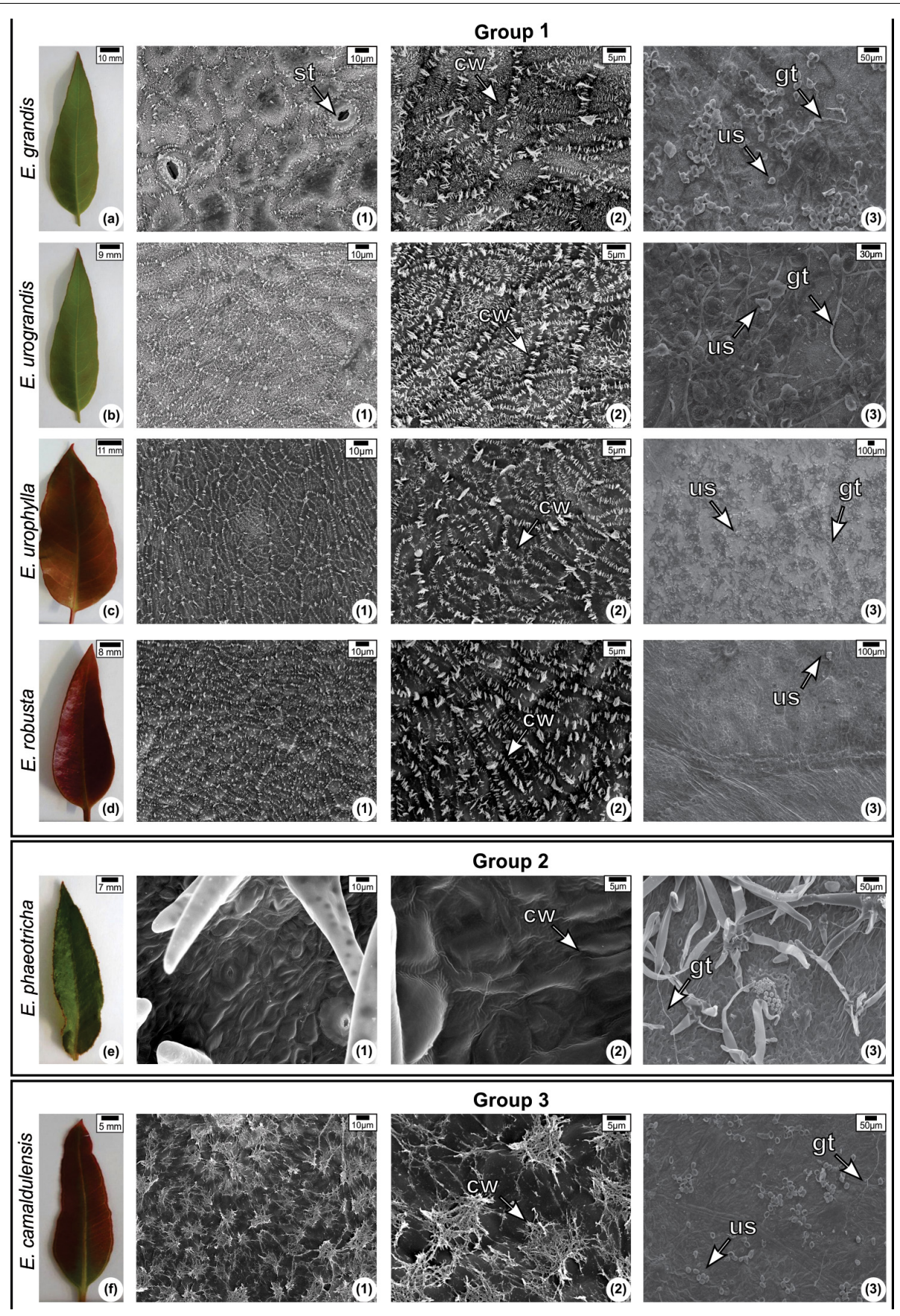

FIGURE 5 | Leaf morphology (a-f) and scanning electron micrograph of the adaxial surface of the leaves of Eucalyptus species non-inoculated (1-2) and inoculated (3) with Austropuccinia psidii at 144 h.a.i Epicuticular wax morphology: Group I-platelets; Group II-Wax sheet; Group III-Tubes or threads. (1) and (2) were observed using different magnifications (1,100x and 3,000x, respectively). CW, cuticular wax; ST, stomata; GT, germination tube; US, Uredospore.

pattern (Steinbauer et al., 2009), but this was differed from the observations of Guzmán et al. (2014) who described the epicuticular wax arrangements as plates with different orientations. Previous studies demonstrated that topography is important for the formation of appressoria (Read et al., 1992; Marques et al., 2013). We believed in a correlation of epicuticular morphology as a determining factor to Eucalyptus susceptibility or resistance. However, this characteristic is better related with the cuticular wax chemical composition. It is clear that $A$. psidii infects species with different cuticular morphologies suggesting that the morphology it is not the key factor for susceptibility.

Eucalyptus spp. have more than one mechanism (preformed and induced resistance) responsible for their resistance against 
A. psidii. The cuticular chemical composition is strongly related to the susceptibility of Eucalyptus grandis and Eucalyptus phaeotricha. However, our data suggest that there are many cuticular signals that act at different stages of fungal infection, uredospore germination, appressorium formation, invasion and survival on the eucalyptus leaves, corroborating the hypothesis that the Eucalyptus spp. resistance to A. psidii is related to synergistic preformed and induced resistance mechanisms that should be studied in more detail.

\section{AUTHOR CONTRIBUTIONS}

IS and MQ designed the research. IS, ML, AB, BT, EF, TC, JM, and LS performed the experiments. IS, TC, JM, and BV analyzed the data. IS, MQ, TC, JM, and CL wrote and revised the manuscript. IS, MQ, JM, and CL contributed through discussions.

\section{REFERENCES}

Alfenas, A. C., Zauza, E. A. V., Mafia, R. G., and Assis, T. F. (2004). Clonagem e Doenças Do Eucalipto. Viçosa, MG: Editora UFV.

Asha, K. R., Priyanga, S., Hemmalakshmi, S., and Devaki, K. (2017). GCMS Analysis of the Ethanolic Extract of whole plant Drosera indica L. J. Pharmacogn. Phytochem. Res. 9, 685-688. doi: 10.25258/phyto.v9i2. 8149

Beenken, L. (2017). Austropuccinia: a new genus name for the myrtle rust Puccinia psidii placed within the redefined family Sphaerophragmiaceae (Pucciniales). Phytotaxa 297, 53-61. doi: 10.11646/phytotaxa. 297.1.5

Bini, A. P. (2016). Estudo Molecular do Desenvolvimento de Puccinia psidii Winter in vitro e no Processo de Infecção em Eucalyptus grandis. Ph.D. thesis, University of São Paulo, Piracicaba.

Bini, A. P., Quecine, M. C., Silva, T. M., Silva, L. D., and Labate, C. A. (2018). Development of a quantitative real-time PCR assay using SYBR Green for early detection and quantification of Austropuccinia psidii in Eucalyptus grandis. Eur. J. Plant Pathol. 150, 735-746. doi: 10.1007/s10658-0171321-7

Cahoon, E. B., Cranmer, A. M., Shanklin, J., and Ohlrogge, J. B. (1994). Delta-6 Hexadecenoic acid is synthesized by the activity of a soluble Delta-6 palmitoylacyl carrier protein desaturase in Thunbergia alata endosperm. J. Biol. Chem. $44,519-526$.

Carnegie, A. J., and Lidbetter, J. R. (2012). Rapidly expanding host range for Puccinia psidii sensu lato in Australia. Australas. Plant Pathol. 41, 13-29. doi: 10.1007/s13313-011-0082-6

Carvalho, A. D. O., Alfenas, A. C., Maffia, L. A., and Carmo, M. G. F. (1998). Resistance of Eucalyptus species, progenies and provenances to Puccinia psidii. Pesq. Agropec. Bras. 33, 139-147.

Casuga, F. P., Castillo, A. L., and Corpuz, M. J. T. (2016). GC-MS analysis of bioactive compounds present in different extracts of an endemic plant Broussonetia luzonica (Blanco) (Moraceae) leaves. Asian Pac. J. Trop. Biomed. 6, 957-961. doi: 10.1016/j.apjtb.2016.08.015

Chong, J., Soufan, O., Li, C., Caraus, I., Li, S., Bourque, G., et al. (2018). MetaboAnalyst 4.0: towards more transparent and integrative metabolomics analysis. Nucleic Acids Res. 46, 486-489. doi: 10.1093/nar/ gky310

Cioffi, G., Sanogo, R., Vassallo, A., Dal Piaz, F., Autore, G., Marzocco, S., et al. (2006). Pregnane glycosides from Leptadenia pyrotechnica. J. Nat. Prod. 69, 625-635. doi: 10.1021/np050493r

Coutinho, T. A., Wingfield, M. J., Alfenas, A. C., and Crous, P. W. (1998). Eucalyptus rust: a disease with the potential for serious international implications. Plant Dis. 82, 819-825. doi: 10.1094/PDIS.1998.82. 7.819

\section{FUNDING}

This study was supported by the Fundação de Amparo à Pesquisa do Estado de São Paulo-FAPESP (Grant 2014/16804-4). We thank the FAPESP for its fellowship awards to AB (2013/075966), EF (2017/11026-1), and JM (2012/25315-1). We also thank Coordenação de Aperfeiçoamento de Pessoal de Nível Superior (CAPES) for their fellowship awards to IS, ML, BT and BV.

\section{ACKNOWLEDGMENTS}

We thank Dr. Beatriz Appezato da Glória (ESALQ/USP, Brazil) for providing the structure for the epicuticular morphology analysis. We also thank Dr. Elliot Watanabe Kitajima from NAP/MEPA (ESALQ/USP, Brazil) for support with the SEM analysis.

Cuadros-Inostroza, A., Caldana, C., Redestig, H., Kusano, M., Lisec, J., PeñaCortés, H., et al. (2009). TargetSearch - a Bioconductor package for the efficient preprocessing of GC-MS metabolite profiling data. BMC Bioinformatics 10:428. doi: 10.1186/1471-2105-10-428

Dianese, J. C., Moraes, T. S. A., and Silva, A. R. (1984). Response of Eucalyptus to field infection by Puccinia psidii. Plant Dis. 68, 314-316. doi: 10.1094/PD69-314

Faramarzi, M. A., Aghelnejad, M., Yazdi, M. T., Amini, M., and Hajarolasvadi, N. (2008). Metabolism of androst-4-em-3, 17-dione by the filamentous fungus Neurospora crassa. Steroids 73, 13-18. doi: 10.1016/j.steroids.2007.06.008

Ferreira, F. A. (1981). Ferrugem de eucalipto - ocorrência, temperatura para germinação de uredósporos, produção de teliósporos, hospedeiro alternativo e resistência. Fitopatol. Bras. 6, 603-604.

Freitas, C. A. S., Vieira, I. G. P., Sousa, P. H. M., Muniz, C. R., Gonzaga, M. L. C., and Guedes, M. I. F. (2016). Carnauba wax p-methoxycinnamic diesters: characterization, antioxidant activity and simulated gastrointestinal digestion followed by in vitro bioaccessibility. Food Chem. 196, 1293-1300. doi: 10.1016/ j.foodchem.2015.10.101

Giblin, F. R., and Carnegie, A. J. (2014). Puccinia psidii (Myrtle rust) - Australian host list. Version current at 23 Oct. 2014. Available at: http://www.anpc.asn.au/ myrtle-rust

Glen, M., Alfenas, A. C., Zauza, E. A. V., Wingfield, M. J., and Mohammed, C. (2007). Puccinia psidii: a threat to the Australian environment and economy a review. Australas. Plant Pathol. 36, 1-16. doi: 10.1071/AP06088

Golebiowski, M., Malinski, E., Bogus, M. I., Kumirska, J., and Stepnowski, P. (2008). The cuticular fatty acids of Calliphora vicina, Dendrolimus pini and Galleria mellonella larvae and their role in resistance to fungal infection. Insect. Biochem. Mol. Biol. 38, 619-627. doi: 10.1016/j.ibmb.2008. 03.005

Gullberg, J., Jonsson, P., Nordstrom, A., Sjostrom, M., and Moritz, T. (2004). Design of experiments: an efficient strategy to identify factors influencing extraction and derivatization of Arabidopsis thaliana samples in metabolomics studies with gas chromatography/mass spectrometry. Anal. Biochem. 331, 283-295. doi: 10.1016/j.ab.2004.04.037

Guzmán, P., Fernández, V., Graça, J., Cabral, V., Kayali, N., Khayet, M., et al. (2014). Chemical and structural analysis of Eucalyptus globulus and E. camaldulensis leaf cuticles: a lipidized cell wall region. Front. Plant Sci. 5:481. doi: $10.3389 /$ fpls.2014.00481

Hallam, N. D., and Chambers, T. C. (1970). The leaf waxes of the genus Eucalyptus L'heritier. Aust. J. Bot. 18, 335-386. doi: 10.1071/BT9700335

Hansjakob, A., Riederer, M., and Hildebrandt, U. (2011). Wax matters: absence of very-long-chain aldehydes from the leaf cuticular wax of the glossy11 mutant of maize compromises the pre penetration processes of Blumeria graminis. Plant Pathol. 60, 1151-1161. doi: 10.1111/j.1365-3059.2011. 02467.x 
Hoffman, D. E., Jonsson, P., Bylesjö, M., Trygg, J., Antti, H., Eriksson, M. E., et al. (2010). Changes in diurnal patterns within the Populus transcriptome and metabolome in response to photoperiod variation. Plant Cell Environ. 60, 1151-1161. doi: 10.1111/j.1365-3040.2010.02148.x

Horbowicz, M., Brenac, P., and Obendorf, R. L. (1998). Fagopyritol B1, O-aD-galactopyranosyl-( $1 \rightarrow 2)$-D-chiro-inositol, a galactosyl cyclitol in maturing buckwheat seeds associated with desiccation tolerance. Planta 205, 1-11. doi: $10.1007 / \mathrm{s} 004250050290$

Horridge, G. A., and Tamm, S. L. (1969). Critical point drying for scanning electron microscopic sthdy of ciliary motion. Science $163,817-818$. doi: 10.1126 /science. 163.3869 .817

Inuyang, E. N., Butt, T. M., Beckett, A., and Archer, S. (1999). The effect of crucifer epicuticular waxes and leaf extracts on the germination and virulence of Metarhizium anisopliae conidia. Mycol. Res. 103, 419-426. doi: 10.1017/ S0953756298007333

Kanehisa, M., and Goto, S. (2000). KEGG: kyoto encyclopedia of genes and genomes. Nucleic Acids Res. 28, 27-30. doi: 10.1093/nar/28.1.27

Karnovsky, M. J. (1965). A formaldehyde-glutaraldehyde fixative of high osmolality for use in electron microscopy. J. Cell. Biol. 27, 137-138.

Kawanishi, T., Uemastu, S., Kakishima, M., Kagiwada, S., Hamamoto, H., Horie, H., et al. (2009). First report of rust disease on Ohia and the causal fungus in Japan. J. Gen. Plant Pathol. 75, 428-431. doi: 10.1007/s10327-009-0202-0

Koch, K., Bhushan, B., and Barthlott, W. (2010). "Multifunctional plant surfaces and smart materials," in Handbook of Nanotechnology, ed. B. Bhushan (New York, NY: Springer Press), 1399-1436.

Kolattukudy, P. E., Rogers, L. M., Li, D. X., Hwang, C. S., and Flaishman, M. A. (1995). Surface signaling in pathogenesis. Proc. Natl. Acad. Sci. U.S.A. 92, 4080-4087. doi: 10.1073/pnas.92.10.4080

Kopka, J., Schauer, N., Krueger, S., Birkemeyer, C., Usadel, B., Bergmüller, E., et al. (2005). GMD@CSB.DB: the Golm Metabolome Database. Bioinformatics 21, 1635-1638. doi: 10.1093/bioinformatics/bti236

Kumar, J., Paul, B., Nebapure, S. M., and Singh, S. (2017). Comparative GCMS analysis of two Brassica rapa L. varieties for identification of volatile compounds. Chem. Sci. Rev. Lett. 6, 884-889.

Lazniewska, J., Macioszek, V. K., and Kononowicz, A. K. (2012). Plant-fungus interface: the role of surface structures in plant resistance and susceptibility to pathogenic fungi. Physiol. Mol. Plant Pathol. 78, 24-30. doi: 10.1016/j.pmpp. 2012.01.004

Leite, T. F. (2012). Estabelecimento de um Patossistema Modelo e Análise da Interação Molecular Planta-Patógeno entre eucalyptus grandis e Puccinia psidii Winter por meio da técnica de Rna-seq. Ph.D. thesis, College of Agriculture "Luiz de Queiroz" University of São Paulo, Piracicaba.

Leite, T. F., Moon, D. H., Lima, A. C. M., Labate, C. A., and Tanaka, F. A. O. (2013). A simple protocol for whole leaf preparation to investigate the interaction between Puccinia psidii and Eucalyptus grandis. Australas. Plant Pathol. 42, 79-84. doi: 10.1007/s13313-012-0179-6

Lytovchenko, A., Beleggia, R., Schauer, N., Isaacson, T., Luendorf, J. E., Hellmann, H., et al. (2009). Application of GC-MS for the detection of lipophilic compounds in diverse plant tissues. Plant Methods 5, 1-11. doi: 10.1186/17464811-5-4

Marques, J. P. R., Amorim, L., Spósito, M. B., and Appezzato-da-Glória, B. (2013). Histopathology of postbloom fruit drop caused by Colletotrichum acutatum in citrus flowers. Eur. J. Plant Pathol. 135, 783-790. doi: 10.1007/s10658-0120120-4

McKinney, H. H. (1923). Influence of soil, temperature and moisture on infection of wheat seedlings by Helminthosporium sativum. J. Agric. Res. 26, 195-217.

Miranda, A. C., Moraes, M. L. T., Tambarussi, E. V., Furtado, E. L., Mori, E. S., Silva, P. H. M., et al. (2013). Heritability for resistance to Puccinia psidii Winter rust in Eucalyptus grandis Hill ex Maiden in Southwestern Brazil. Tree Genet. Genomes 9, 321-329. doi: 10.1007/s11295-012-0572-x

Moussa, T. A. A., and Almaghrabi, O. A. (2016). Fatty acid constituents of Peganum harmala plant using gas chromatography-mass spectroscopy. Saudi J. Biol. Sci. 23, 397-403. doi: 10.1016/j.sjbs.2015.04.013

Nikolova, M., Aneva, I., and Berkov, S. (2016). GC-MS metabolic profiling and free radical scavenging activity of Micromeria dalmatica. Biol. Nyssana 7, 159-165. doi: $10.5281 /$ zenodo. 200415
Quecine, M. C., Bini, A. P., Romagnoli, E. R., Andreote, F. D., Moon, D. H., and Labate, C. A. (2014). Genetic variability in Puccinia psidii populations as revealed by PCR-DGGE and T-RFLP markers. Plant Dis. 98, 16-23. doi: 10.1094/PDIS-03-13-0332-RE

Quecine, M. C., Leite, T. F., Bini, A. P., Regiani, T., Franceschini, L. M., Budzinski, I. G. F., et al. (2016). Label-free quantitative proteomic analysis of Puccinia psidii uredospores reveals differences of fungal populations infecting eucalyptus and guava. PLoS One 11:e0145343. doi: 10.1371/journal.pone.014 5343

Racovita, R. C., Peng, C., Awakawa, T., Abe, I., and Jetter, R. (2015). Very-longchain-3-hydroxy fatty acids, 3-hidroxy fatty acid methyl esters and 2-alkanols from cuticular waxes of Aloe arborescens leaves. Phytochemistry 113, 183-194. doi: $10.1016 /$ j.phytochem.2014.08.005

Rajeswari, J., and Rani, S. (2015). GC-MS analysis of phytochemical compounds in the ethanolic extract of root Lawsonia inermis Linn. Int. J. ChemTech Res. 7, 389-399.

Read, N. D., Kellock, L. J., Knight, H., and Trewavas, A. J. (1992). “Contact sensing during infection by fungal pathogens," in Perspective in Plant Cell Recognition, eds J. A. Gallow and J. R. Green (Cambridge: Cambridge University Press), 137-172.

Reisige, K., Gorzelanny, C., Daniels, U., and Moerschbacher, B. M. (2006). The C28 aldehyde octacosanal is a morphogenetically active component involved in host plant recognition and infection structure differentiation in the wheat stem rust fungus. Physiol. Mol. Plant Pathol. 68, 33-40. doi: 10.1016/j.pmpp.2006. 05.006

Roux, J., Greyling, I., Coutinho, T. A., Verleur, M., and Wingfield, M. J. (2013). The Myrtle rust pathogen, Puccinia psidii, discovered in Africa. IMA Fungus 4, 155-159. doi: 10.5598/imafungus.2013.04.01.14

Samtani, M. N., and Jusko, W. (2007). Quantification of dexamethasone and corticosterone in rat biofluids and fetal tissue using highly sensitive analytical methods: assay validation and application to a pharmacokinetic study. Biomed. Chromatogr. 21, 585-597. doi: 10.1002/bmc.788

Schauer, N., Steinhauser, D., Strelkov, S., Schomburg, D., Allison, G., Moritz, T., et al. (2005). GC-MS libraries for the rapid identification of metabolites in complex biological samples. FEBS Let. 579, 1332-1337. doi: 10.1016/j.febslet. 2005.01.029

Serrano, M., Coluccia, F., Torres, M., L'Haridon, F., and Metraux, J. P. (2014). The cuticle and plant defense to pathogens. Front. Plant Sci. 5:274. doi: 10.3389/fpls. 2014.00274

Silva, D. E. M., Azevedo, L. A. S., and Poltronieri, T. P. S. (2014). Avaliação da resistência de espécies de eucalipto à ferrugem (Puccinia psidii Winter). Summa Phytopathol. 40, 54-62. doi: 10.1590/S0100-5405201400010 0008

Song-Jiang, C., Yong-Cai, L., Yan, Y., Yong-Hong, G., and Yi, W. (2014). Solvent effects on the ultrastructure and chemical composition of cuticular wax and its potential bioactive role against Alternaria alternate in Pingguoli pear. J. Integr. Agric. 13, 1137-1145. doi: 10.1016/S2095-3119(13) 60374-3

Stashenki, E. E., and Martínez, J. R. (2012). "GC-MS analysis of volatile plant secondary metabolites," in Gas Chromatography in Plant Science, Wine Technology, Toxicology and Some Specific Applications, eds B. Salih and Ö. Çelikbiçak (London: InTech), 247-270.

Steinbauer, M. J., Davies, N. W., Gaertner, C., and Derridj, S. (2009). Epicuticular waxes and plant primary metabolites on the surfaces of juvenile Eucalyptus globulus and E. nitens (Myrtaceae) leaves. Aust. J. Bot. 57, 474-485. doi: 10.1071/ BT09108

Takahashi, S. S. (2002). Ferrugem do Eucalipto: Índice de Infecção, Análise Temporal e Estimativas de Danos Relacionados à Intensidade da Doença no Campo. Doctoral Dissertation, Universidade Estadual Paulista, Botucatu.

Tessmann, D. J., and Dianese, J. C. (2002). Hentriacontane: a leaf hydrocarbon from Syzygium jambos with stimulatory effects on the germination of uredósporos of Puccinia psidii. Fitopatol. Bras. 27, 538-542. doi: 10.1590/S010041582002000500017

Tucker, D., Wallis, I., Bolton, J., Marsh, K., Rosser, A., Brereton, I., et al. (2010). A metabolomic approach to identifying chemical mediators of mammalplant interactions. J. Chem. Ecol. 36, 727-735. doi: 10.1007/s10886-0109803-5 
Viana, R. G., Tuffi-Santos, L. D., Demuner, A. J., Ferreira, F. A., Ferreira, L. R., Ferreira, E. A., et al. (2010). Quantification and chemical composition of epicuticular wax of Eucalyptus leaves. Planta Daninha 28, 753-758. doi: 10. 1590/S0100-83582010000400007

Vijisaral, E. D., and Arumugam, S. (2014). GC-MS analysis of bioactive constituents of Indigofera suffruticosa leaves. J. Chem. Pharm. Res. 6, 294-300.

Xavier, A. A., Alfenas, A. C., Matsuoka, K., and Hodges, C. S. (2001). Infection of resistant and susceptible Eucalyptus grandis genotypes by urediniospores of Puccinia psidii. Australas. Plant Pathol. 30, 277-281. doi: 10.1071/AP 01038

Yeats, T. H., and Rose, J. K. C. (2013). The formation and function of plant cuticles. Plant Physiol. 163, 5-20. doi: 10.1104/pp.113.222737

Zabka, M., Pavela, R., and Prokinova, E. (2014). Antifungal activity and chemical composition of twenty essential oils against significant indoor and outdoor toxigenic and aeroallergenic fungi. Chemosphere 112, 443-448. doi: 10.1016/j. chemosphere.2014.05.014

Zabka, V., Stangl, M., Bringmann, G., Vogg, G., Riederer, M., and Fildebrandt, U. (2007). Host surface properties affect pre penetration processes in the barley powdery mildew fungus. New Phytol. 177, 251-263. doi: 10.1111/j.1469-8137. 2007.02233.x
Zamprogno, K. C., Furtado, E. L., Marino, C. L., Bonine, C. A. V., and Dias, D. C. (2008). Utilização de análise de segregantes agrupados na identificação de marcadores ligados a genes que controlam resistência à ferrugem (Puccinia psidii) em Eucalyptus spp. Summa Phytopathol. 34, 253-255. doi: 10.1590/ S0100-54052008000300009

Zauza, E. A. V., Alfenas, A. C., Old, K., Couto, M. F., Graça, R. N., and Maffia, L. A. (2010). Myrtaceae species resistance to rust caused by Puccinia psidii. Australas. Plant Pathol. 39, 406-411. doi: 10.1071/AP10077

Conflict of Interest Statement: The authors declare that the research was conducted in the absence of any commercial or financial relationships that could be construed as a potential conflict of interest.

Copyright (c) 2019 Santos, Lopes, Bini, Tschoeke, Verssani, Figueredo, Cataldi, Marques, Silva, Labate and Quecine. This is an open-access article distributed under the terms of the Creative Commons Attribution License (CC BY). The use, distribution or reproduction in other forums is permitted, provided the original author(s) and the copyright owner(s) are credited and that the original publication in this journal is cited, in accordance with accepted academic practice. No use, distribution or reproduction is permitted which does not comply with these terms. 